Document downloaded from:

http://hdl.handle.net/10251/168947

This paper must be cited as:

Alemany-Bordera, J.; Del Val, E.; García-Fornes, A. (2020). Assessing the Effectiveness of a Gamified Social Network for Applying Privacy Concepts: An Empirical Study with Teens. IEEE Transactions on Learning Technologies. 13(4):777-789. https://doi.org/10.1109/TLT.2020.3026584

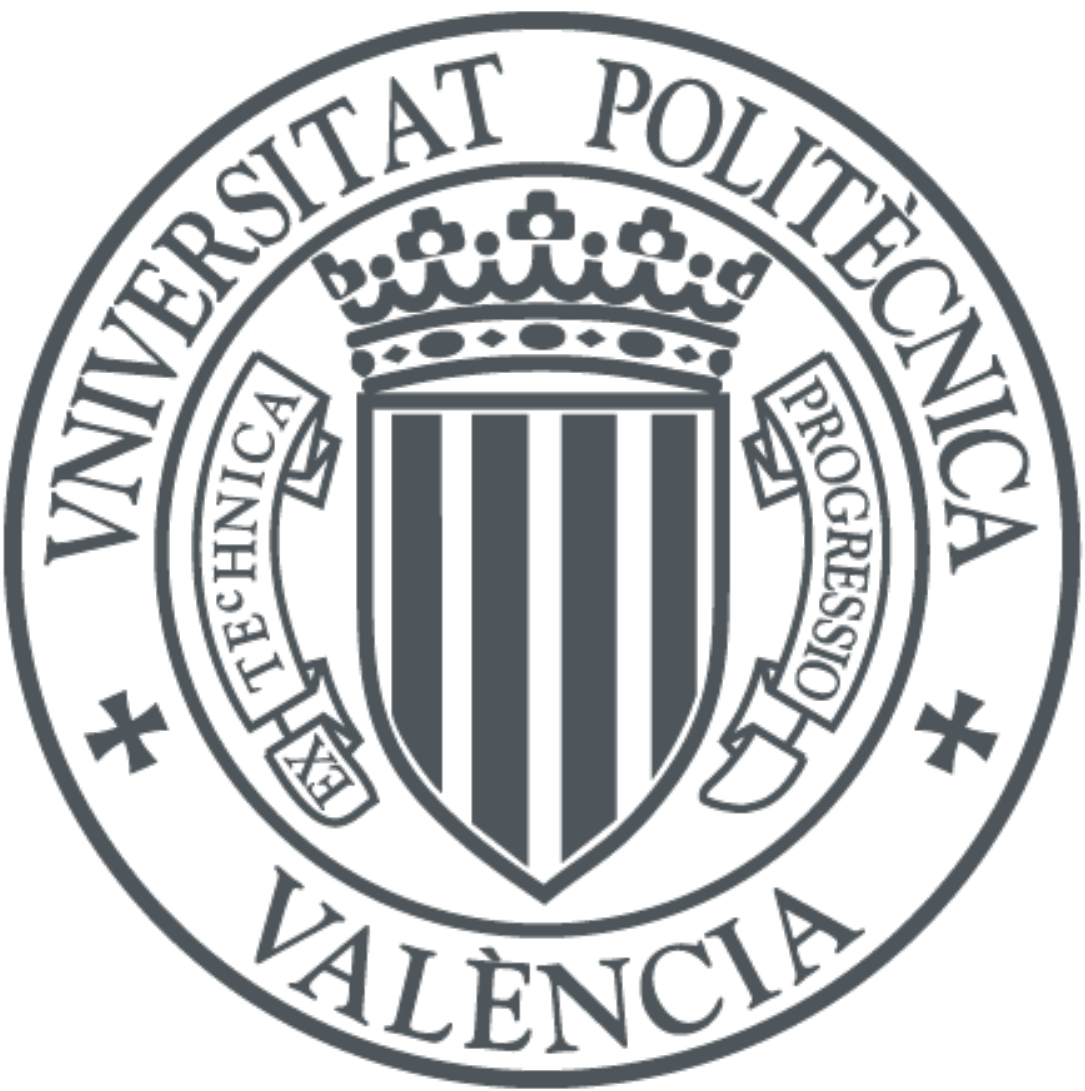

The final publication is available at

https://doi.org/10.1109/TLT.2020.3026584

Copyright IEEE

Additional Information 


\title{
Assessing the Effectiveness of a Gamified Social Network for Applying Privacy Concepts: An Empirical Study with Teens
}

\author{
J. Alemany, E. Del Val, and A. García-Fornes
}

\begin{abstract}
The concept of privacy in online social networks (OSNs) is a challenge, especially for teenagers. Previous works deal with teaching about privacy using educational online content and media literacy. However, these tools do not necessarily promote less risky behaviors and do not allow the assessment of users' behavior after the learning period. Moreover, few research studies about the effects of social gamification have been performed for this population segment (i.e., teenagers). To address this problem, we propose the use of gamification in an OSN called PESEDIA to facilitate the teaching/learning process and assess its effectiveness in promoting suitable privacy behaviors. We tested our proposal comparing teenagers' performance in two editions of a course about social networks and privacy (with and without gamification) for one month. We measured the impact of gamification in the participants' behaviors towards privacy concepts as a consequence of the privacy teaching/learning process and the participants' engagement in the educational process. The results show that there are significant differences in participants' behavior regarding privacy and engagement in the gamified social network. Moreover, there is also a significant difference in participants' engagement for the gamified male participants. The gamified social network proposed in this work may be relevant and useful for educators who wish to develop and enhance teenagers' privacy skills, or for a broader base of aspects related to the development of digital competences and technology in education.
\end{abstract}

Index Terms-Gamification, learning technologies, privacy, social networks, teenagers.

\section{INTRODUCTION}

$\mathbf{S}$ OCIAL networks are an important element in the daily lives of teenagers (ages from 13 to 17). According to the latest Pew Research Center report [1], most teenagers have a profile on an Online Social Network (OSN). This report also points out that there is no clear consensus among teenagers about the effect that OSNs have on their lives. OSNs make it easier for them to keep in touch and interact with others (i.e., friends and family or others with similar interests), but they also entertain them and provide a new way of learning

Manuscript received July 10, 2019; revised March 6, 2020; accepted September 24, 2020. Date of current version September 24, 2020. This work was supported by the Spanish Government project TIN2017-89156-R and the FPI grant BES-2015-074498. (Corresponding author: E. Del Val)

J. Alemany and A. García-Fornes are with the Valencian Research Institute for Artificial Intelligence (VRAIN), Universitat Politècnica de València, Camino de Vera s/n, Valencia, Spain (e-mail: jalemany1@dsic.upv.es; agarcia@dsic.upv.es).

E. Del Val is with the Departamento de Informática e Ingeniería de Sistemas (DIIS), Escuela Universitaria Politécnica de Teruel, c/ Atarazana 2, Teruel, Spain (e-mail: edelval@unizar.es).

Digital Object Identifier 10.1109/TLT.2020.3026584 things. However, as teenagers benefit from the use of social networks, they are also exposed to the risks [2]-[5] when interacting, publishing, or sharing information in OSNs. This lack of knowledge about the opportunities and risks derived from the use of OSNs (as new consumers and users) may have negative consequences on their lives. Therefore, they need a proper education to enhance their current and future performance in social networks.

To promote a critical and safe use of OSNs, researchers and governments have emphasized the role of school education to teach teenagers how to safely interact with others in OSNs [6]. Specifically, the European Union has developed initiatives to support safer online access and use of OSNs for children [7], [8]. An example is The European Strategy for a Better Internet for Children [8] that has as goals, among others, promotion of the production of creative and educational online content for children as well as to increase children's awareness of the Internet and to empower them to use it safely and responsibly. In addition, online safety has been formally included in school curricula in many European countries through media literacy to improve skills to avoid risks in OSNs [6], [9]. However, it is unclear if these mechanisms can effectively increase privacy awareness (i.e., the attention and understanding of an individual regarding privacy aspects) [10] and prevent unsafe behaviors in OSNs.

Recently, an approach that is rising in popularity is the use of game mechanics and game components in a non-game context (i.e., gamification) [11]. Gamification as an educational learning tool is a powerful approach for dealing with the teaching/learning of tedious or complex tasks [12], such as the learning of safe privacy behaviors in social networks. This approach is powerful due to its ability to teach and reinforce not only knowledge but also important practical skills that might be useful for their daily lives. On the other hand, existing studies have highlighted the influence of OSNs for improving usage levels and perceived levels of learning in students [13]. The properties offered by social networks such as centrality, communication, and connectivity significantly influence learners' performance. Therefore, taking into account the context of the learning goal (social networks, opportunities, and risks), it could be interesting to use both approaches to improve users' learning performance. Moreover, the use of a real social network allows us to assess the users' behavior in real scenarios after the learning period.

The aim of this work is to analyze the effect of introducing gamification in a social network so that students could 
autonomously learn the functionality of the network and the options and consequences of the different privacy options. We assessed the application of what was learned by the students in the network and analyzed the influence that gamification had on this process. Therefore, this study contributes to the research field in the following ways: 1) by illustrating the value of social gamification for introducing the social network features to new users (reducing the "learning curve") and for learning and promoting the application of privacy behaviors that prevent users from performing actions that could have negative consequences; and 2) by exploring the effects of social network gamification on teenagers by gender and age. Moreover, the gamified social platform proposed in this work may be relevant and useful for educators who wish to develop and enhance teenagers' privacy skills, or for a broader base of aspects related to the development of digital competences and technology in education. The technical and design contributions that the paper makes to the development of learning technologies are: 1) the development of a social network for educating teenagers about safe privacy behaviors and social network features as a unique tool in the "learning by doing" approach; and 2) the design of the learning strategy integrated into the social network with the gamification system.

In the remainder of this article, we first highlight relevant research for education about privacy in social networks and the advantages of gamification (Section III), which will lead to the postulation of four research questions. Then, we discuss the method of our study (Section III) and report the results (Section IV). We end this article by discussing the implications of the findings, what we learned compared with current significant research, and the limitations of the study (Section V). Finally, we conclude this article by answering our research questions and by presenting future work (Section VI).

\section{LITERATURE REVIEW}

\section{A. Educating Teenagers about OSN Privacy}

Teenagers grow up surrounded by a wide range of social media platforms and most of them are both consumers and creators of content in them. However, they are not always aware or have a limited perception of the implications of their online actions and the risks that they can encounter. Several educational strategies have been carried out by education centers and public administrations to leverage teenage users' awareness of privacy risks and to reduce their exposure to cyberbullying or experiences that make them feel uncomfortable in OSNs [6], [14]-[16]. Previous studies that have evaluated the impact of educational initiatives suggest that these strategies are successful in increasing awareness about online risks [17], [18]. However, the research community considers that awareness and confidence do not necessarily promote less risky behavior among young people [19]. This result is aligned with the number of young people who report negative online experiences despite the initiatives carried out by education institutions [19].

As an alternative to educational materials, the use of technological tools [20], [21] has been proposed as a means of offering practical experience to learn appropriate attitudes and behaviors when using social network sites. Inoue et al. [20] presented an online and offline version of a tool that helps students to understand privacy risks in online social networks. They performed an experiment in a practical lesson in a school where the teacher interacted with the students using the tool, creating scenarios where the privacy of the students might be compromised. After each scenario, the teacher and students analyzed the effects and potential consequences of their performed actions. A survey conducted after the experiment concluded that the students retained the knowledge about how to handle personal information in OSNs. Wang et al. [21] proposed the development of education tools with high levels of usability and effectiveness to increase knowledge about privacy risk in online sites. The authors presented a prototype based on an educational game that incorporates ideas collected from online crowds to increase the awareness of online privacy. An extension of this proposal was presented in [22]. Along the same lines, Li et al. [23] proposed the development of labware for teaching location privacy in online services. This labware was the mechanism to provide a deeper knowledge about the topic of privacy and to increase the students' privacy awareness. Although the tools proposed in these previous works made it easier to learn safer behaviors on social networks, most were what-if web tools based on hypothetical scenarios that did not put the user into a real social network environment or in his/her own real scenarios.

\section{B. Social Networks and Gamification in Education}

Although the use of technological tools has a positive effect on the users' learning process of online privacy, these tools are isolated from the context of the educational goal. Therefore, they cannot determine whether the knowledge learned (reflected as awareness and concern about privacy) will promote privacy-seeking behavior in real scenarios (i.e., the actions that users get involved in to safeguard their information on the social network). Studies that focus on using technological tools for improving the teaching/learning process have highlighted the influence of social networks on improving usage levels and perceived levels of learning in students [13]. Research works such as [24] have tested the power of social networks to improve engagement and satisfaction with the course. Properties of social networks such as communication, interaction, and information are translated into support, motivation, and experience. These can reduce the anxiety levels of students [25] and turn the educational expectations into reality by applying a real social context in the teaching/learning process that requires real decisions.

The inclusion of gamification is of interest to the design of activities that are oriented to getting positive feedback (possibly in a competitive environment). Recent research in this field [11], [26], [27] has emphasized the gamification features in order to facilitate a user-centered, autonomous, and flexible learning environment that allows students to follow their own learning path and encourage users to pursue their own goals. The reviewed papers about the application of gamification are mainly focused on MOOCs and e-learning sites [12]. Moreover, according to Dicheva et al. [28], many 
works focus on the use of gamification in education, but the majority only describe some game mechanisms and dynamics without empirical research that validates the effectiveness of including game elements in learning contexts. Hanus et al. [29] also mention that although the benefits of gamification are mentioned in many works, there is still a need for deep empirical research on the effectiveness of gamification.

Social gamification aims to bring together gamification and social networking to combine the potential of the two approaches in order to create compelling socially-driven user experiences. From an educational perspective, social networks facilitate communication and interactions between students (and with teachers) and highlight relevant content elements. Their potential can also be harnessed to cooperate and create meaningful conversations in learning interactions. On the other hand, gamification stimulates motivational aspects such as participation and engagement with learning content and with other participants. In addition, different skills such as competition, collaboration, and adaptation can be enhanced depending on the gamification instruments used [11]. There is little previous research in social gamification [13], [30], and, to the best of our knowledge, none focus on the teenage population or the context of improving users' online privacy through the learning of privacy-seeking behaviors. Therefore, we set out to address the following research question:

RQ1 Is there a significant impact on teenage users' learning and behavior about online privacy between social network configuration with gamification and configuration without gamification?

Furthermore, we want to know if the gamification of the social network improves teenage users' engagement to the social network (i.e., breaking the barrier of joining a new social network site and consolidating them as regular users). Therefore, we set out to address the following research question:

RQ2 Is there a significant impact on teenage users' engagement between social network configuration with gamification and configuration without gamification?

\section{Individual Differences}

Different authors have shown that personal characteristics play a role in the individual's behavior. Acquisti et. al. [31] analyze how different biases on information introduction and personal characteristics influence users' behaviors and decisions. Al-Rahmi et. al. [32] test how education impacts learning differently depending on students' gender. Koivisto and Hamari [33] study how individual learners interpret game elements differently in highly unique ways. Pedro et al. [34] perform a gender study in a virtual learning environment with gamification. The results indicate that gamification contributed to improving student performance in the case of male students and did not have any effect on motivation and performance in the female students. However, this work was a preliminary study with 16 students; hence, the results cannot be generalized. In this work, we aim to statistically validate conclusions regarding the influence of gender in gamified learning environments. We investigate the impact of gender and age on teenage users regarding their learning about privacy and social network features, safe privacy behaviors, and engagement in the gamified social network. Therefore, we set out to address the following research questions:

RQ3a Do female teenage users learn and have more privacyseeking behavior in the gamified social network than their male counterparts?

RQ3b Do female teenage users engage more in the gamified social network than their male counterparts?

RQ4a Does the age of teenage users influence learning and privacy-seeking behavior in the gamified social network?

RQ4b Does the age of teenage users influence engagement in the gamified social network?

\section{EXPERIMENTAL DESIGN}

\section{A. Study Site}

Introduction to Social Networks (ISNs) is a course that briefly covers the basics of social networking and provides students with basic competency for deciding which privacy policy is most appropriate when they share information in social networks. The course is aimed at teenagers who are starting with the use of social networks. They are among the heaviest users of social networking [35]. Moreover, this particular group is developmentally vulnerable to online risks such as depression, sexting, and cyberbullying [36]-[39].

The course lasts one month and has a total workload of 4.5 hours that matches with on-site teaching lessons. We only have three on-site lessons and the course should be a fun learning experience. An ethics consent letter was obtained from each participant prior to the course. The participants knew that anonymized data would be collected about their activity on the social network. During the course, we provided teenagers with access to our social network, PESEDIA [40] (similar to Facebook), where only they could use it and practice the learned knowledge acquired during the course. PESEDIA was active and accessible 24/7. At the end of the course, we analyzed the behaviors of the teenagers in the social network to evaluate the success of the course, and we presented them with some conclusions. Previous course edition experiences had shown low motivation and participation rates in the proposed activities. Providing teenagers with tools to motivate participation may therefore be a sound approach to improve learning, safe privacy behaviors and engagement. For this reason, we added a gamification module in PESEDIA.

\section{B. Instruments}

In order to compare the performance as well as the attitude towards social gamification, we carried out an experiment using two configurations of our social network. One configuration consisted of using only the instruments provided by a social network similar to Facebook. The other configuration consisted of including a module in the social network to provide gamification instruments. The social network, called PESEDIA, was the same for both configurations of the experiment. A 
TABLE I

Summary of Instruments Remarking the Main Features of the Different Means and Targeted Benefits

\begin{tabular}{|c|c|c|}
\hline Instrument & Features & Approach and targeted benefit \\
\hline $\begin{array}{l}\text { Social } \\
\text { networking }\end{array}$ & $\begin{array}{l}\text { Posting, sharing, comments, liking, friends, } \\
\text { activity river, user profiles, private } \\
\text { messaging, surveys, external guidance } \\
\text { (tutorials and activities) }\end{array}$ & $\begin{array}{l}\text { - Cooperation and communication among participants } \\
\text { - Boost participation, collaborative work, and community building } \\
\text { - Promote student-driven discussion }\end{array}$ \\
\hline $\begin{array}{l}\text { Social } \\
\text { networking } \\
\text { with } \\
\text { gamification }\end{array}$ & $\begin{array}{l}\text { Posting, sharing, comments, liking, friends, } \\
\text { activity river, user profiles, private } \\
\text { messaging, surveys, points, badges, } \\
\text { achievements, score, status, leaderboard }\end{array}$ & $\begin{array}{l}\text { - Cooperation, communication, and competition among participants } \\
\text { with gamification } \\
\text { - Boost participation, collaborative work, and community building } \\
\text { - Promote student-driven discussion } \\
\text { - Motivate participation through public leaderboard comparison }\end{array}$ \\
\hline
\end{tabular}

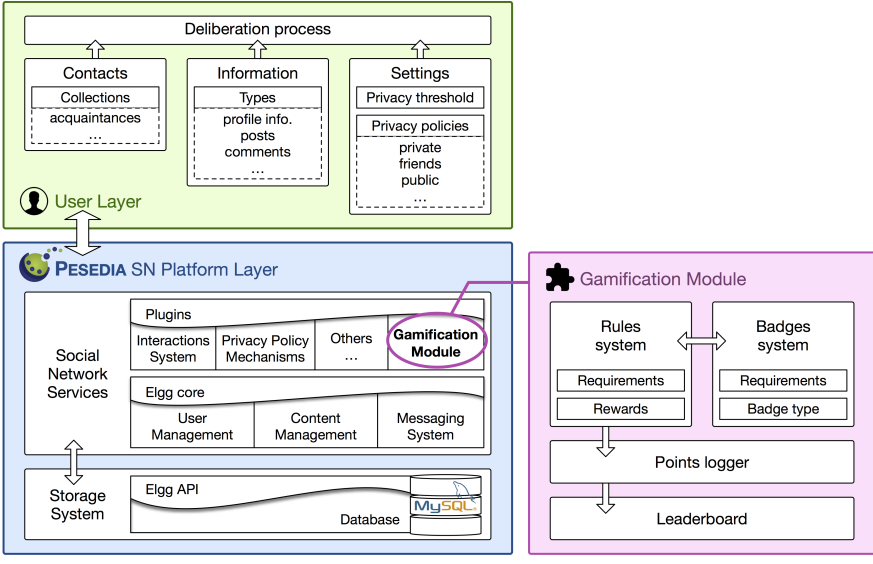

Fig. 1. Block diagram that represents the architecture of PESEDIA. Also represented is the relevant plugin for this work: the Gamification Module.

summary of the instruments used for each configuration is presented in Table I]

PESEDIA is an online social network for educational and research purposes. PESEDIA was designed as a tool for the teaching/learning of OSN features and to increase concern, awareness, and seeking behavior on privacy, especially in the case of children and teenagers who are just beginning to use OSNs. The main goals of PESEDIA include: (i) the design and development of new metrics to analyze and quantify privacy risks [41], [42]; (ii) the application of methods to influence users' behavior towards safer actions regarding their privacy [43]; and (iii) the evaluation and testing of new proposals with real users [44]. The underlying implementation of PESEDIA uses Elgg [45], which is an open-source engine that is used to build social environments. The environment provided by this engine is similar to other social networks (e.g., Facebook). We developed each functionality in PESEDIA through modules following the design principles of the Elgg engine (see Figure 11. The modules allow us to enable and disable online features of the social network at any time, adapting them to the needs of the experiment. Moreover, the use of our social network allowed users to interact with each other and to perform the course activities.

The first configuration was based on the last non-gamified course edition done. It was a non-gamified configuration of

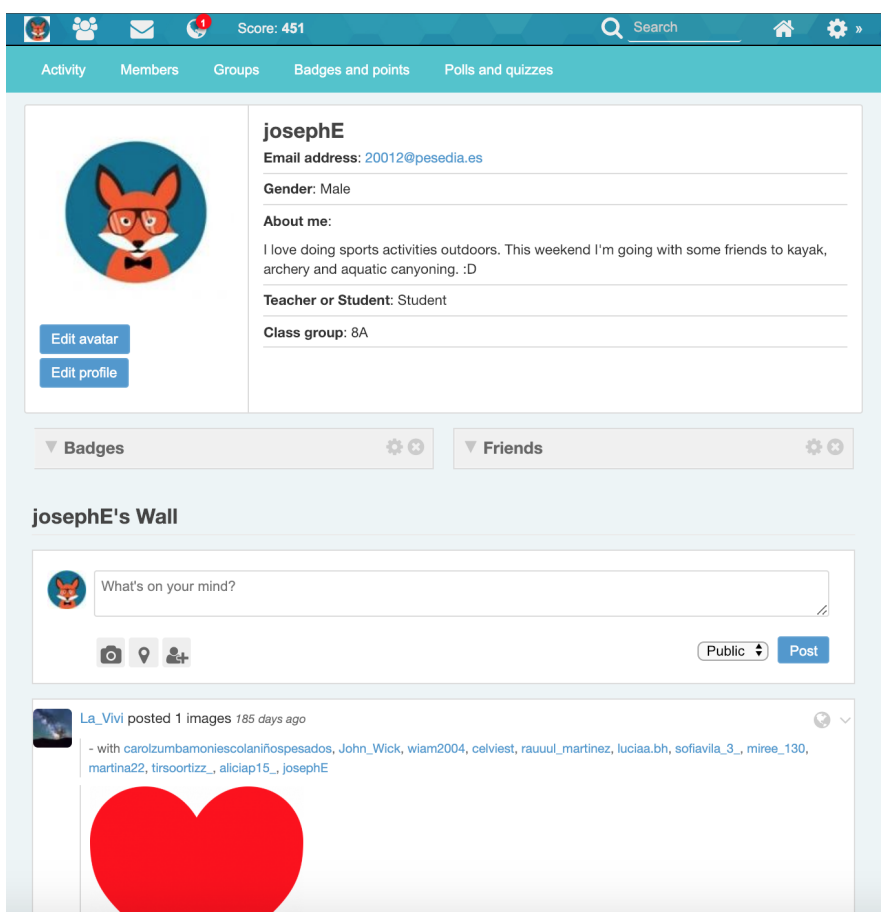

Fig. 2. User wall of the social network PESEDIA. This screenshot belongs to the gamified social network. The non-gamified configuration does not include the "Score" representation in the top bar or the "Badges-and-points" menu.

Pesedia, which provided the environment to perform the activities planned in each lesson. Figure 2 depicts the different elements that the social network offered to users: a profile view with their profile elements presented (in the center of the figure); a wall, where users post their publications and comments (at the bottom of the figure, accessible via the "Activity" tab or the profile icon in the top bar); friendship management (group icon in the top bar); private messaging service (message icon in the top bar); and other instruments that are easily identifiable in the figure. The difference between the Pesedia course editions is the gamification module, so the "Score" and "Badges-and-points" tab were not available in the non-gamified course. The other instruments used in this configuration were mainly tutorials and activities. The difference between these instruments was related to the grade of teaching assistance needed to complete them. 
The second configuration was a gamified PESEDIA that allowed students to complete the activities planned in each lesson autonomously at their own pace without the intervention of teaching assistants. The gamification design included in PESEDIA offers users the possibility to choose what activities to complete and there are no penalties for poor activity performance. We have considered game design elements at two levels of abstraction: (i) educational gamification design principles, and (ii) game mechanics [28], [46]. The gamification design principles selected are based on the idea of progress. The intention was to present practical lessons in stages that scale by difficulty (i.e., scaffolded instruction), but that each user can accommodate to his/her own pace and needs [29]. We considered a set of stages of mastery following the stages established by Dreyfus when looking at how people engage with systems [47]. The stages of mastery are the following:

- Newcomer: The user who just arrived to the social network. He/she has created an account in the social network and has logged in.

- Rookie: Similar to a newcomer but with information already in hand about some privacy aspects. He/she is on his/her way toward figuring out how the social network works and what functionalities it offers.

- Trainee: Users have increased their practice in a wide variety of typical social network actions such as sharing and/or commenting on other publications, uploading photos, likes or labeling friends. Users also achieve a deeper knowledge about the options that the social network offers in order to restrict the visibility of their actions. The situations that they deal with in the social network are stored in order to provide a basis for future recognition of similar situations that could appear in the future.

- Expert: The user starts to think about the different configurations of privacy policies and which ones are the most suitable by considering different scenarios and types of information (i.e., profile items or posts). He/she learns how to create different personalized audience groups and how to use them to restrict the audience of a publication.

- Master: The expert performer in the social network has reached the final stage in the step-wise improvement of privacy awareness and good practices that we have been following. The user repertoire of experienced situations is now quite broad, and he/she can intuitively dictate an appropriate action for each specific situation.

The game mechanics proposed are based on the following three key elements:

- Points: These allow us to see how users are interacting within the social network, design for outcomes, and make appropriate adjustments. We have considered two types of points: experience points, which are used to track the user activity in the social network; and skills points, which are assigned to specific activities within the social network that reflect whether the user has acquired certain skills (see Figure 3 ).

- Badges: These offer a visual representation of progress and are given for special achievements. We have considered different kind of badges: Status and Experi-

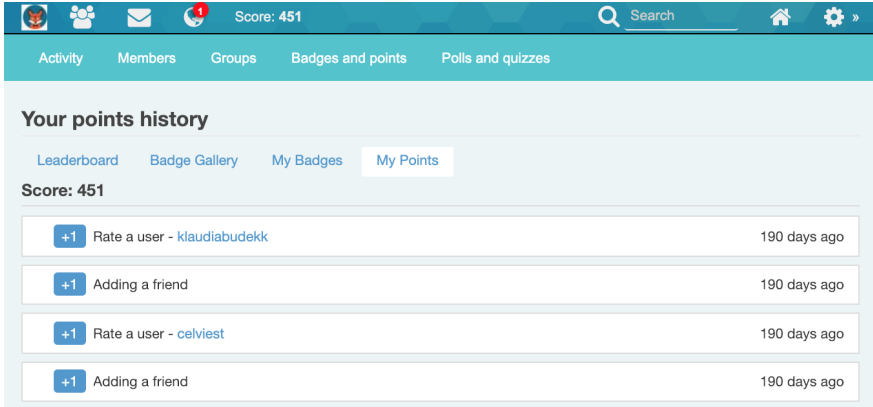

Fig. 3. View of "My Points" with a registry of the latest points obtained for a specific user.

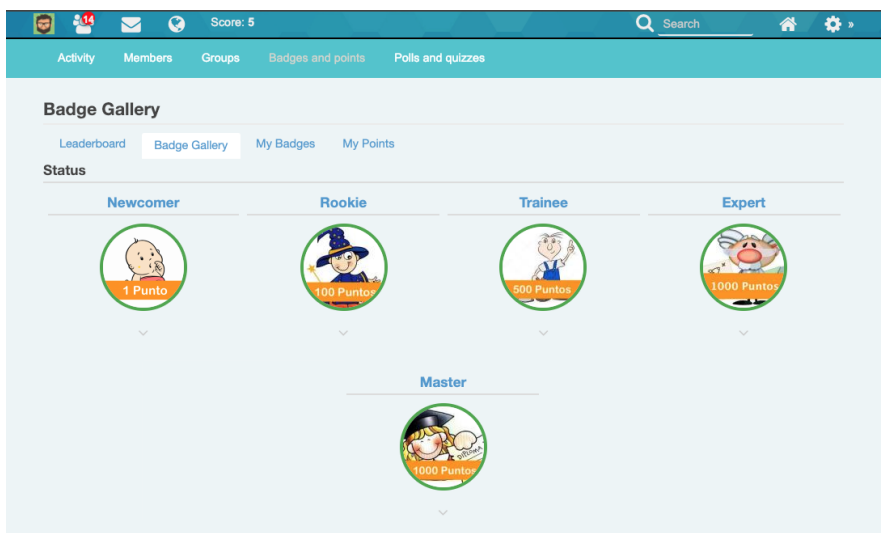

Fig. 4. View of the "Badge Gallery" with all of the badges the user has not achieved yet.

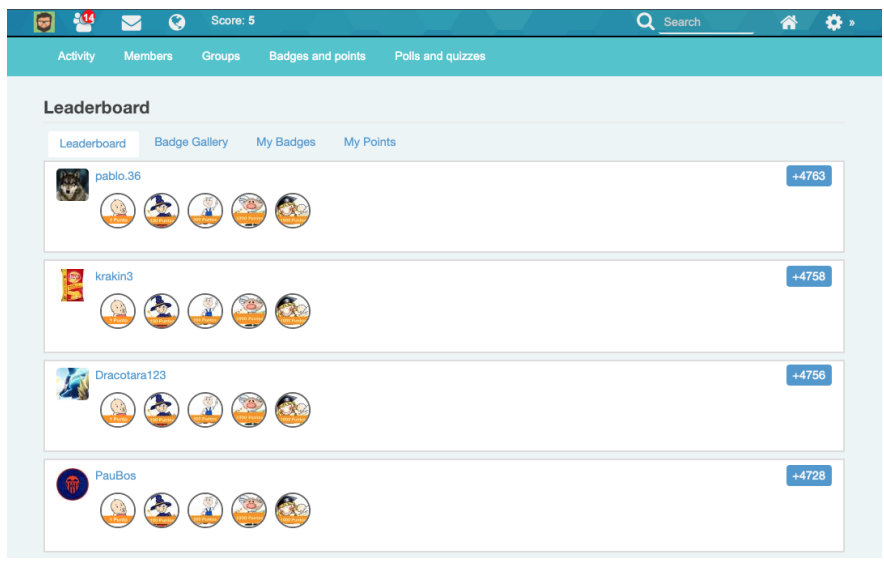

Fig. 5. View of the "Leaderboard" with a top-ten ranking of the users with the most points.

ence badges. The stages of mastery (Newcomer, Rookie, Trainee, Expert, and Master) are represented as Status badges, while activities are represented as Experience badges. Each Status badge is composed of a set of Experience badges (see Figure 4).

- Leaderboard: The goal of the leaderboard is to make simple comparisons. Based on the points and badges, users are ranked on a leaderboard that encourages engagement through competition (see Figure 5).

All of these instruments included in the gamification module were used to complete learning activities. Each activity had 
a specific number of points associated to it (i.e., experience points or skills points). Moreover, an activity was associated with the requirements to obtain a badge. To obtain a badge, the students had to complete several activities depending on the level of the badge (i.e., Newcomer, Rookie, Trainee, Expert, or Master), thus giving them a sense of progression towards mastery and also providing points on the achievement of each badge. The different activities/badges were gradually enabled during each lesson so that the participants could complete the activities/badges and have time to practice the learned knowledge acquired before continuing with the other activities/badges. In other words, a lesson had a set of activities/badges that were enabled at the beginning of the lesson, and once the participants completed them, they had time to practice them before the next lesson started. Based on the number of activities performed (represented as badges and points obtained), the leaderboard offered the possibility to see other students' positions in the ranking for competing and sharing their achievements. Once they achieved all of the badges (from a lesson, or from the whole course), the participants could still get some extra points for performing actions related to the activities. Therefore, they could continue practicing the knowledge acquired on the social network but without activity support.

\section{Participants}

A total of 405 teenagers participated in the experiment. Of these, we excluded the participants who did not complete all of the control lessons (13 participants) as well as the participants who decided not to participate (5 participants did not $\log$ into PESEDIA). Finally, 387 participants completed the experiment (196 females, 191 males, 86 12-year-olds, 199 13-year-olds, and 102 14-years-olds, $\mathrm{M}_{\text {age }}=13.04$, range: $12-$ 14 years old). We included the participants in the experiment taking into account their age in order to have a sample of the teenage population (participants older than 12 years old). All of the selected participants were attending high school in different school centers of the Valencia area at the time of the experiment. When the participants enroll, they were assigned to one of the two groups of the experiment based on when they sign up. The social network without gamification was administered to a group of 178 teenagers (97 females, 81 males, 38 12-year-olds, 93 13-year-olds, and 47 14-yearolds, $\left.\mathrm{M}_{\mathrm{age}}=13.05\right)$. The social network with gamification was administered to a group of 209 teenagers (99 females, 110 males, 48 12-year-olds, 106 13-year-olds, and 55 14-year-olds, $\left.\mathbf{M}_{\mathrm{age}}=13.03\right)$.

\section{Procedure}

Experimentation took place during the summer period. Both course editions had a duration of one month and had the same content and activities. The experiment was carried out on the PESEDIA social network where both configurations were applied: one configuration without the gamification module, and another with the gamification module enabled. To prevent interferences, we included a registry controller (using a secret token) to avoid undesired registrations that could affect the security of the participants and the experiment. The participants of the experimental group who used the social network without gamification took the course first. Then the course was taken by the participants of the experimental group who used the social network with gamification. During the period of the experiment, the participants had access to the PESEDIA social network to share their experiences and feelings.

We organized three on-site lessons of 90 minutes in equipped labs at the university to use as control points of the experiment. In these lessons, activities were delivered sequentially to be completed in the same session or from home. These three on-site lessons were distributed at three points in time: lesson 1, at the beginning of the one-month period; lesson 2, in the middle; and lesson 3, at the end. The aim of these lessons was to clarify any doubts that might arise among the participants about the functionality and features of the social network. Each lesson started with a brief explanation of the activities that they should try to complete during the lesson, and then participants had time to interact using the social network and complete the different activities. The activities had textual descriptions. Students were assisted during the lessons to clarify doubts that could arise during the performance of the activities. In the first lesson, we introduced PESEDIA to the participants and they signed up on the social network. Then, they had to complete some activities that focused on customizing their user profiles, setting up their general setting options, and building their friendship relations (low-medium difficulty). In the second lesson, they had to complete activities that focused on interacting and posting, choosing their audience (medium-high difficulty). In the third (and last) lesson, the participants had to complete an extra activity (challenge). Finally, to conclude the course, we also presented them with a course summary regarding their behaviors and answers to the survey.

\section{E. Measures and Data Analysis}

During the experimentation, a log system was activated to record all of the participants' actions in order to analyze them after the experiment. Information such as the privacy policies chosen for profile items, general setting options, and posts were used to assess the users' privacy-seeking behavior. The rate of private policies used over the total number of privacy decisions chosen was computed for each participant. Information such as the amount of content created, and the rate of activity and survey completions were used to calculate the users' engagement with the educational process. All of these values were normalized on a $0-1$ scale, except for the content-created variable. The Shapiro-Wilk test was used to check the normality of the data distribution for the variables. That indicated to us that we had to use non-parametric tests since the data gathered did not follow a normal distribution. Therefore, Mann-Whitney and Kruskal-Wallis tests were used to analyze differences between groups.

\section{Results}

In this section, we present the participants' results regarding the behavior and activities performed on PESEDIA for both 
configurations (Non-Gamified and Gamified). We also test the research questions considered above about the participants' behaviors towards privacy concepts as a consequence of the privacy teaching/learning process, the participants' engagement with the social network, differences in gender and/or age behavior of the participants and their attitude towards the instruments used. Note that the Shapiro-Wilk normality test was run to analyze the distribution values of the private privacy policies rate and the participation rate of the participants (Tables II] III] and IV) collected from the social network PESEDIA for running the appropriate statistical tests. The results showed the non-normality of the data (since p-values are less than $\alpha=0.05$ ). Therefore, non-parametric statistical tests were applied to investigate our research questions.

\section{A. Privacy-seeking Behavior}

The participants' behavior regarding privacy was measured through the usage that participants made of PESEDIA. We specially analyzed the data collected from the privacy policies of the participants' profile items, general setting options, and publications. The data collection was done for the duration of the experiment, which was one month.

Figure 6 shows the participants' behavior regarding different privacy decisions on the social network, which are split into three dimensions: the privacy policy of profile items (e.g., name, phone number, etc.), the general privacy setting options (e.g., friend list visibility, "who is allowed to tag me", etc.), and the privacy policy of publications. The values represent the rate distribution of private privacy policies used by the participants (ranging from 0 to 1 , where 0 means that no private privacy policies were used while 1 means that only private privacy policies were used). Private privacy policies include: Friends, personalized access lists (also known as collections), and Only me. An analysis of the results reveals three notable points for discussion. First, the profile items that contain the most sensitive information of participants such as name, email, or phone number had more permissive privacy policies in the Non-Gamified configuration than in the Gamified configuration. Although we explained to the participants how to change these privacy policies in both course editions, they figured out how to customize them better in the Gamified configuration. In contrast, in the Non-Gamified configuration, the vast majority of participants shared their personal profile data with public policies (all of the quartiles of the boxplot are in the 0 value) except for a few participants (representing the outliers). Second, the general setting options about privacy are an instrument that participants seldom take care of, regardless of whether there is gamification. Both scenarios have a median of value 0 for private privacy policies (represented as a line in the middle of the boxplot figure). The participants changed their privacy setting options towards more restrictive privacy policies only in a few cases, more in the Gamified configuration than in the Non-Gamified configuration (where all of the quartiles of the boxplot are in the 0 value). The most changed privacy setting options were "who is allowed to tag me", "who is allowed to publish on my wall", and the visibility of the friend list, in that order. Third,

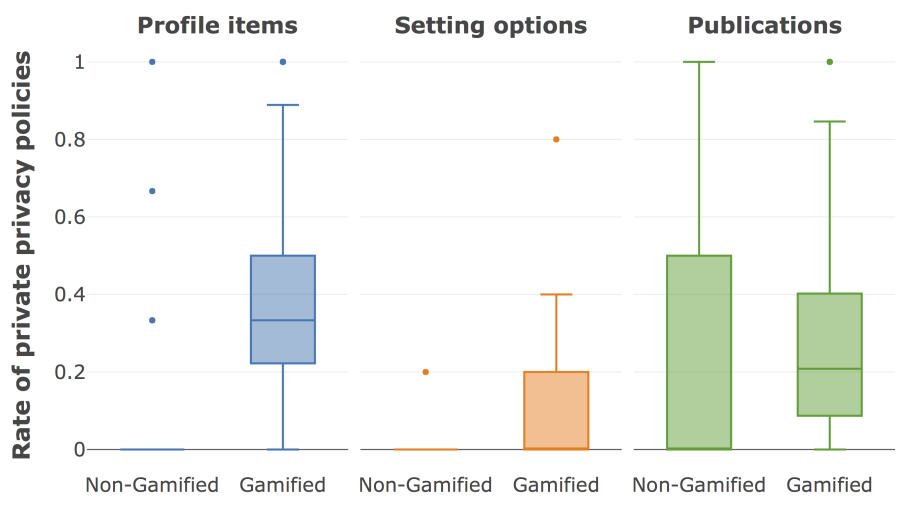

Fig. 6. Participants' behaviors regarding privacy decisions on profile items, general setting options, and publications on PESEDIA for Non-Gamified and Gamified configurations. Values (ranging from 0 to 1 ) represent the rate distribution of private privacy policies (e.g., Only me, Collections, or Friends) used by the participants, where 0 means that no private privacy policies were used and 1 means that only private privacy policies were used.

the posting action, which is the main action for interacting with others in a social network, also has a median value of 0 for the Non-Gamified configuration. However, there are no outlier points (in contrast to the other dimensions for the Non-Gamified configuration). This means that a significant portion of participants also used private privacy policies. For the Gamified configuration, the participants followed more restrictive privacy policies for posting actions. Even so, we observed that, in this configuration, the privacy policies were slightly less restrictive than for the profile items. This is normal since the information sensitivity of the profile item dimension is probably higher than for the publication dimension. Finally, for all of the dimensions about privacy decisions in the Non-Gamified configuration, the participants used the social network without taking too much care about who could access their information. Research works such as [48] highlight OSN users' learning through regrets of their actions due to bad decisions as the most common practice. In contrast, the use of gamification to introduce and educate users about privacy aspects in social networks as shown in our experiments may help to improve these hurdles.

Research question RQ1 was tested in order to determine whether or not there is a significant difference in privacy behaviors between Gamified and Non-Gamified PESEDIA. We collected the data from the privacy policies of the participants' profile items, settings, and publications for the duration of the experiment, which was one month. The rate data of the private policies was normalized for each participant. Due to the nonnormality of the variables and the number of samples, we used the Mann-Whitney test $(\alpha=.05)$. For this test, we calculated the mid p-value since its Type I error rate is closer to the nominal level. We investigated the research questions taking into account the theory of the null hypothesis as well as the Mann-Whitney test. In statistical hypothesis testing, a Type I error is the rejection of a true null hypothesis. Thus, we are able to reject the null hypothesis $\left(\mathrm{H}_{0}\right)$ to accept the alternative $\left(\mathrm{H}_{1}\right)$.

To answer research question RQ1 about how the gamification of the social network impacts the participants' behaviors 
TABLE II

Summary of Descriptive Statistics, the Shapiro-Wilk Normality Test, and the ManN-Whitney Test For InVESTigating Research QUESTIONRQ1

\begin{tabular}{|c|c|c|c|c|c|c|c|c|c|c|c|}
\hline \multirow[b]{2}{*}{ Variable } & \multirow[b]{2}{*}{ Category } & \multicolumn{6}{|c|}{ Descriptive statistics } & \multicolumn{2}{|c|}{ Shapiro-Wilk test } & \multicolumn{2}{|c|}{ Mann-Whitney test } \\
\hline & & $\mathrm{N}$ & Mean & Std. Dev. & Std. Err. & Min. & Max. & Statistic W & $\mathrm{p}$-value & Statistic U & p-value \\
\hline \multirow[t]{2}{*}{ Profile privacy } & Non-Gamif. & 178 & .013 & .096 & .007 & 0 & 1 & .120 & $<.001$ & 3108 & $<.001$ \\
\hline & Gamif. & 209 & .373 & .246 & .017 & & & .939 & $<.001$ & & \\
\hline \multirow[t]{2}{*}{ Settings privacy } & Non-Gamif. & 178 & .001 & .015 & .001 & 0 & 1 & .048 & $<.001$ & 11314 & $<.001$ \\
\hline & Gamif. & 209 & .090 & .124 & .008 & & & .670 & $<.001$ & & \\
\hline \multirow[t]{2}{*}{ Posting privacy } & Non-Gamif. & 126 & .259 & .368 & .033 & 0 & 1 & .706 & $<.001$ & 9642 & $<.001$ \\
\hline & Gamif. & 201 & .265 & .235 & .016 & & & .902 & $<.001$ & & \\
\hline
\end{tabular}

towards privacy concepts and safe practices in social networks, we tested the mean differences between the Gamified and NonGamified social network, especially taking into account the behaviors regarding private privacy policies for the dimensions of the profile, settings, and posting (see Table II). Specifically, we ran the Mann-Whitney test $(\alpha=.05)$ and the results rejected the null hypothesis of similarity for profile, settings, and posting dimensions $(\mathrm{p}$-value $=<.001)$. Therefore, significant differences were found in the impact on the participants' behaviors towards privacy concepts and safe practices in the social network between the Gamified configuration and the Non-Gamified configuration of the social network. Thus, RQ1 was supported.

\section{B. Social Network Engagement}

The participants' engagement with the social network was measured through the actions they did publishing content and completing activities on PESEDIA. We specially analyzed the amount of content created (such as posts, comments, likes, private messages, etc.), the rate of completed activities, and the rate of completed surveys. The data collection was done for the duration of the experiment, which was one month.

Figure 7 shows the distributions of the engagement of the participants in the social network in the experiment taking into account the following three features: the amount of created content (i.e., number of posts, comments, likes, etc.), the rate of completed activities (i.e., the number of completed activities normalized by their total), and the rate of completed surveys. For the content creation column, the values represent the amount of content created by the participants. Both distributions have the same shape, both have a few participants that are very active and produce great amounts of content and a majority of participants who only publish a few publications. Even so, the rate of participation in the Gamified configuration (with a median of about 80 contents created by each participant) is clearly higher than the rate of participation in the Non-Gamified configuration (roughly 15 contents created by each participant). Moreover, the most active participants using the Non-Gamified configuration created the same amount of content as a regular participant using the Gamified configuration. For the activity and survey participation columns, the values represent the rate distribution of completed activities and surveys by each participant. The activities (for both the Non-Gamified and the Gamified

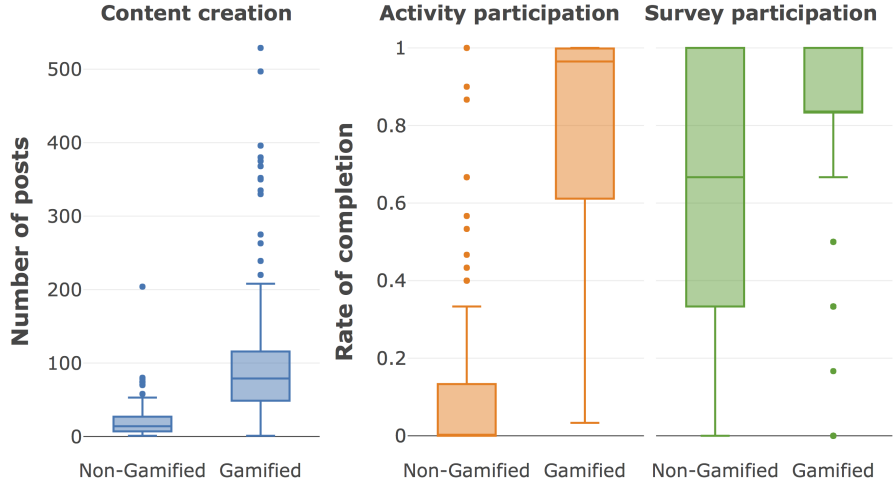

Fig. 7. Participants' engagement based on the amount of content created, the rate of activities completed, and the rate of surveys completed on PESEDIA with and without gamification.

configurations) were focused on improving the learning of the social network features, the privacy-seeking behavior, and the engagement to participate actively. However, in the NonGamified configuration, only a few users participated in the activities. The opposite occured in the Gamified configuration, where the median rate of completed activities was $95 \%$ (represented as a line in the middle of the boxplot figure). In the case of the surveys, the rate of completion was high in both configurations. Nevertheless, the number of completed surveys was slightly better in the Gamified configuration. We considered that the huge difference in activity participation for both configurations could be because gamification provides participants with the autonomy to complete the activities at their own pace, while the Non-Gamified configuration does not provide this advantage.

Research question RQ2 was tested in order to determine whether or not there was a significant difference in social network engagement between configurations. We analyzed the amount of content created by the participants, the activity participation, and the survey participation. The participation rate was normalized for each participant. Due to the nonnormality of the variables and the number of samples, we used the Mann-Whitney test $(\alpha=.05)$. For this test, we calculated the mid p-value since its Type I error rate is closer to the nominal level. We investigated the research questions taking into account the theory of the null hypothesis as well as the Mann-Whitney test. In statistical hypothesis testing, a Type I error is the rejection of a true null hypothesis. Thus, we are 
able to reject the null hypothesis $\left(\mathrm{H}_{0}\right)$ to accept the alternative $\left(\mathrm{H}_{1}\right)$.

To answer research question RQ2 about how the gamification of the social network impacts the participation rates of teenage users, we tested the mean differences between the Gamified and Non-Gamified social network, especially taking into account the variables regarding the amount of content created, and the activities and surveys completed (see Table III). Specifically, we ran the Mann-Whitney test $(\alpha=.05)$ and the results rejected the null hypothesis of similarity for content creation, and the activity and survey completion dimensions ( $\mathrm{p}$-value $=<.001)$. Therefore, significant differences were found in the impact on the participation rates of teenage users in the social network between the Gamified and the NonGamified configuration of the social network. Thus, RQ2 was supported.

\section{Gender and Age Behavior Differences}

Next, we analyze the privacy and engagement behavior of the participants in the social network regarding their gender and age, but only for the Gamified configuration. We want to determine whether gamification instruments affect the participants in a different way according to their gender and age. We analyze the same features as above but split by gender and age. The collection was done for the duration of the experiment, which was one month.

Figure 8 shows the distribution of the engagement of the participants in the social network by gender and age for the Gamified configuration. We analyzed the features to measure the engagement as we did in Section IV-B. The results obtained from the engagement distributions show slightly similar distributions for these features by gender and age. There were only some differences in the engagement distributions by gender. The clearest difference can be seen in the amount of content created on the social network by the male participants, where they obtain the maximum values per participant and also have a higher median than the female participants. No differences were found for gender or age regarding privacy behavior.

Research questions RQ3a, RQ3b, RQ4a, and RQ4b were tested in order to determine whether or not there was a significant difference regarding privacy behavior or engagement in the social network taking into account the gender and age of the participants of the Gamified configuration. We used the features analyzed and normalized for each participant in the Gamified configuration. Due to the non-normality of the variables and the number of samples, we used non-parametric tests. For the tests, we calculated the mid p-value since its Type I error rate is closer to the nominal level. We investigated the research questions taking into account the theory of the null hypothesis. In statistical hypothesis testing, a Type I error is the rejection of a true null hypothesis. Thus, we are able to reject the null hypothesis $\left(\mathrm{H}_{0}\right)$ to accept the alternative $\left(\mathrm{H}_{1}\right)$.

To answer the research questions about how the gender of the participants in the Gamified social network configuration influences privacy behavior (RQ3a and engagement (RQ3b), we tested the mean differences between genders taking into

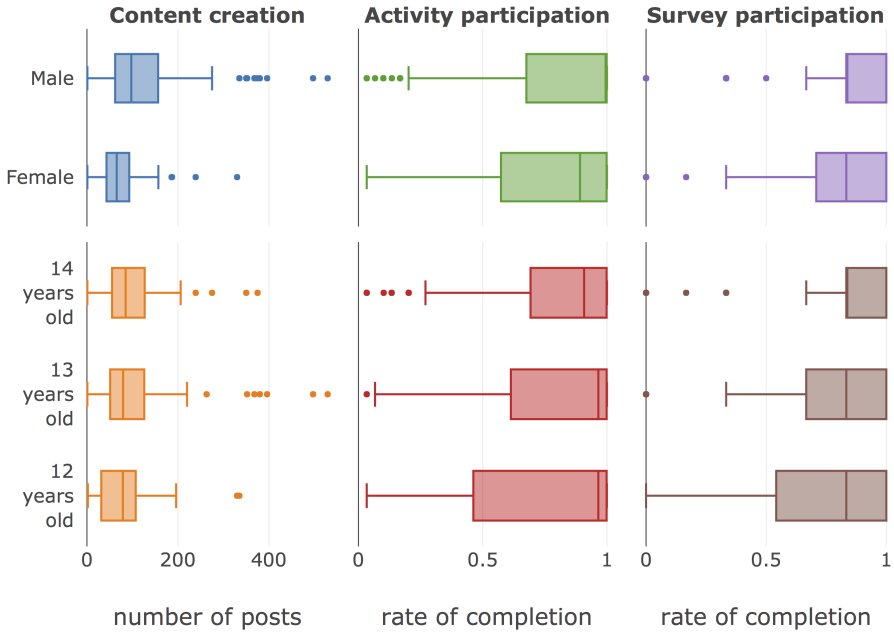

Fig. 8. Participants' engagement split by gender and age for the Gamified PESEDia.

account the variables shown in Table IV Specifically, we ran the Mann-Whitney test $(\alpha=.05)$, and the results rejected the null hypothesis of similarity only for content creation and the activity completion dimensions ( $\mathrm{p}$-value $=<.001$ ). Therefore, significant differences were only found for the impact on the participation rates of teenage users for the gender of the participants regarding content creation and activity participation. Thus, RQ3b was partially supported only for engagement.

To answer the research questions about how the age of the participants in the gamified social network configuration influences privacy behavior (RQ4a) and engagement (RQ4b), we tested the mean differences for three groups(12, 13, and 14-year-olds) taking into account the variables shown in Table IV] Specifically, we ran the Kruskal-Wallis test $(\alpha=.05)$ and the results did not reject the null hypothesis of similarity ( $p$-value $>$.05). Therefore, no significant differences were found in the participants' privacy behavior or engagement in the social network by age. Thus, RQ4a and RQ4b were not supported.

\section{DiscusSiON}

The integration of gamification instruments in non-game contexts to teach people in a practical way about dull, tedious or complex tasks is rising in popularity. The privacy concept, and especially users' privacy on social networks, is a challenge that is highlighted in several research works [49]-[51]. Therefore, the use of gamification in the context of social networks to teach users about privacy and privacy mechanisms of the social network is a perfect match. This combination allows users to be aware of their privacy, and thus be better able to manage complex scenarios to avoid possible leaks of information or regrets. In this work, we have assessed the integration of gamification on a social network through the investigation of four research questions. The aim of these research questions was to measure the effect of gamification on teenage users regarding the learning of privacy and social network features, privacy awareness, and social network engagement. PESEDIA is the social network 
TABLE III

Summary of Descriptive Statistics, the Shapiro-Wilk Normality Test, and the Mann-Whitney Test For InVestigating Research QUESTIONRQ2

\begin{tabular}{|c|c|c|c|c|c|c|c|c|c|c|c|}
\hline \multirow[b]{2}{*}{ Variable } & \multirow[b]{2}{*}{ Category } & \multicolumn{6}{|c|}{ Descriptive statistics } & \multicolumn{2}{|c|}{ Shapiro-Wilk test } & \multicolumn{2}{|c|}{ Mann-Whitney test } \\
\hline & & $\mathrm{N}$ & Mean & Std. Dev. & Std. Err. & Min. & Max. & Statistic W & $\mathrm{p}$-value & Statistic U & p-value \\
\hline Content creation & Non-Gamif. & 178 & 20.247 & 21.825 & 1.636 & 0 & - & .686 & $<.001$ & 4180 & $<.001$ \\
\hline Activity participation & Gamif. & 209 & .777 & .311 & .022 & & & .726 & $<.001$ & & \\
\hline \multirow[t]{2}{*}{ Survey participation } & Non-Gamif. & 178 & .657 & .273 & .020 & 0 & 1 & .846 & $<.001$ & 12934 & $<.001$ \\
\hline & Gamif. & 209 & .777 & .276 & .019 & & & .730 & $<.001$ & & \\
\hline
\end{tabular}

TABLE IV

Summary of Descriptive Statistics, the Shapiro-Wilk Normality Test, and the Non-Parametric Tests of Significance

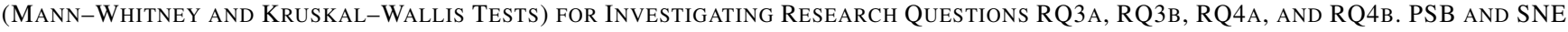

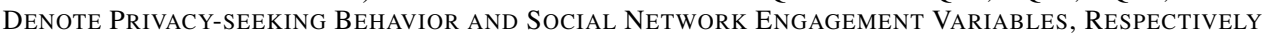

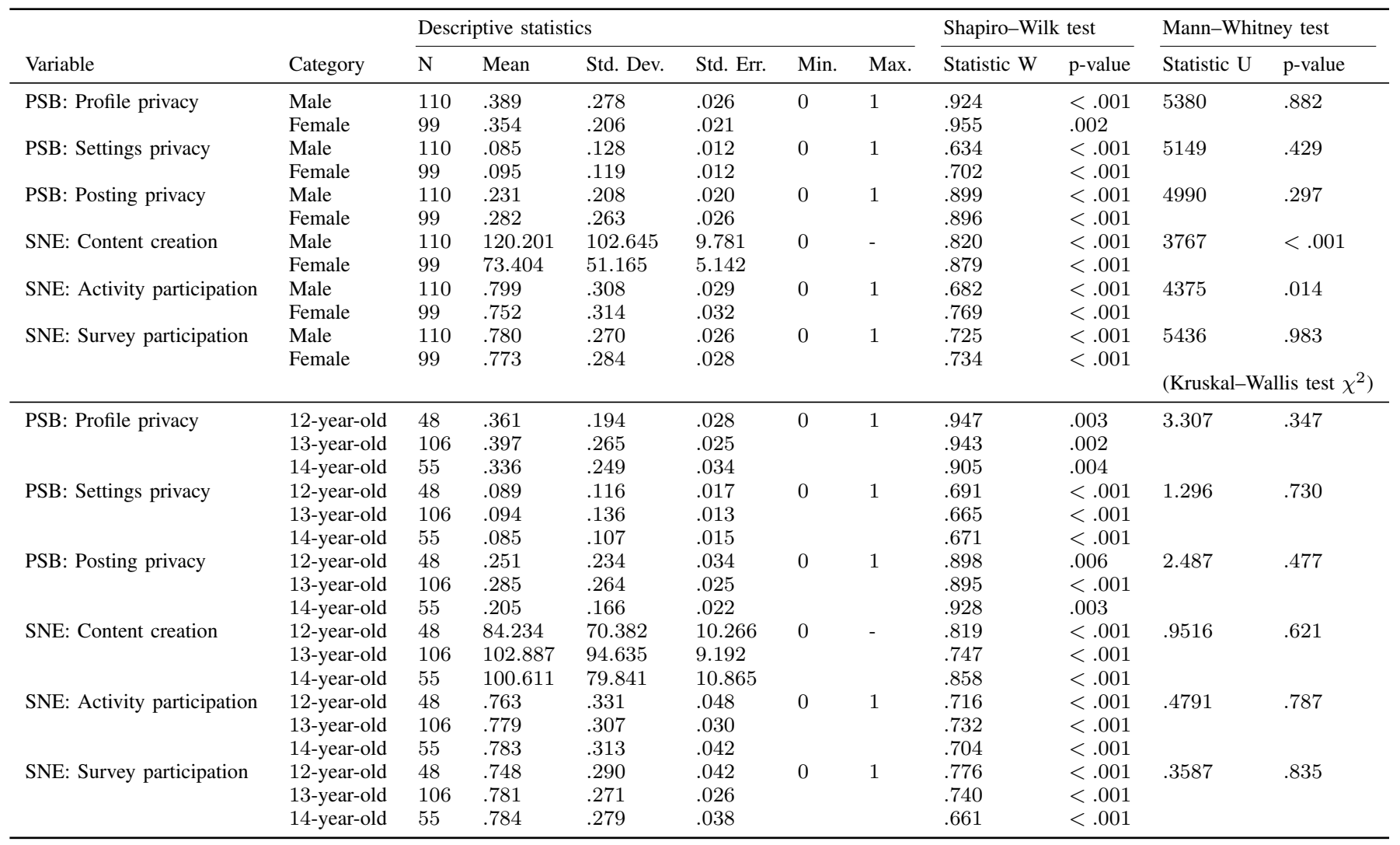

where the gamification instruments were integrated, which is similar to Facebook and has most of the privacy mechanisms of Facebook. To do this, we carried out a short-term, onemonth experiment where two configurations of the social network PESEDIA were used: one with the gamification module enabled, and the other without it. The gamified social network proposed in this work may be relevant and useful for educators who wish to develop and enhance teenagers' privacy skills, or for a broader base of aspects related to the development of digital competences and technology in education.

The direct benefits of using gamification to improve learning have numerous defenders [28], [46], although there are some contexts or features where gamification produces negative effects [29], [52]. In the context of social networks, previous works such as [13], where the combination of gamification instruments with social network instruments is proposed, defend the extra benefits of this union. However, as far as we know, the application of social gamification has not been proven on the teenage population nor with the aim of improving the users' awareness and privacy-seeking behavior. In our work, the results suggest that the gamification designed and integrated into PESEDIA has a positive learning effect on teenagers. They improved their awareness and seeking behavior of privacy, and their interest in the social network was higher when the gamification module was enabled. Specifically, profile items, general setting options, and posts had privacy policies that were more appropriate, and the rate of activity and survey completion was also higher. We did not 
see any negative effects on teenage users' behavior due to the use of gamification instruments. Furthermore, the age and gender of teenagers did not have a relevant effect on how they were influenced by gamification, except in the case of male teenagers who created content slightly more actively than female teenagers. While some studies indicate that females engage more in gamified courses than males [26], our work has extracted the conclusions for a younger population (teenagers). Moreover, our work has also been assessed in a different context (a social network), where studies like [53] have highlighted that male teens disclose more information than female teens. However, testing the effect of gamification on social networks to teach users about privacy should be done by extending the participant population to include other age ranges.

The way gamification is designed and the instruments used can enhance the learning effect on people [27]. Although our results show more awareness of privacy and higher participation rates by teens when the gamification module is active, we do not know with certainty which privacy policies are the most appropriate for a publication. The lack of easy metrics to compute the most appropriate privacy policy for a publication (i.e., the privacy policy that maximizes the social benefit of the user and minimizes his/her loss of privacy) makes our goal an estimation between the usage of the privacy mechanisms and the privacy choice. Therefore, once there is a recognized way of assessing the appropriateness of a privacy policy for users' publications, it will be possible to design gamification instruments that focus on improving the privacy policies chosen for a publication, taking into account all of the factors involved. Some works try to define the best way to measure these factors and combine them [54]-[56]. An interesting next step would be to use them with gamification. Thus, it would be possible to maximize users' learning about privacy concepts through gamification instruments.

Other factors to consider are the time when gamification is used and/or its duration, and what/how many rewards should be designed. In our case, we limited the number of rewards (i.e., badges and points) for each lesson. Thus, the participants had a powerful gamification reinforcement at the beginning of each on-site lesson (and during the course experience) that introduced them to the social networks and accelerated the learning curve [57]. Once the participants achieved the rewards designed in each lesson, no more rewards were activated in the same lesson. Thus, after the learning period (i.e., at the end of each lesson, between lessons, and at the end of the course), the participants used the social network with the knowledge acquired from the activities. Other interesting approaches to be considered would be: varying the gamification time of use to determine the most optimal application time for the participants' learning; or adding punishments/rewards for users when they make bad/good privacy policy choices (e.g., in cases of sensitive information, or conflicts detected between users, etc.). It should always be taken into account that there are different types of users with different social network goals [58].

Despite the valuable conclusions extracted, this study has several limitations. First, the current research was conducted for one month. That is why only a short-term impact on users' privacy behaviors and social network engagement could be measured. As we stated above, we do not know the consequences of long-term usage of gamification instruments and their impact on users' behaviors. It could happen that, after a certain period of time, some users might ignore the knowledge acquired. While the observed immediate effect of gamification was desirable, future research that extends the period of usage could be interesting. Second, as we have highlighted in this work, the lack of easy metrics to measure the appropriate privacy policy for a publication makes us estimate the privacyseeking behavior as the usage of the privacy mechanisms plus the privacy choice. Furthermore, we designed our gamification activities and instruments based on this estimation. Therefore, having a metric that is capable of measuring the appropriate privacy policy for a publication, we would be able to effectively design the gamification elements and assess the effect for improving users' concern, awareness, and seeking behavior on privacy. Finally, the participants considered for the experiments have a certain age distribution (approx. 1214 years old). Therefore, these results cannot be extrapolated to teenage users in general (approx. 12-18 years old) to obtain a broader view of this group of social network users. In order to be able to confirm whether the effects observed in this study are extrapolatable to other populations, we plan to evaluate the performance of gamification for different populations, that is, a more heterogeneous sample of participants with different age ranges and nationalities.

\section{CONCLUSION}

This research work studied the capabilities of social networks and social gamification for educational purposes about the concepts of social networks, especially users' online privacy. We assessed two configurations (with/without gamification), focusing on teenagers' learning and engagement with the educational process. We also statistically compared the two approaches to determine which one provided better results. After a statistical analysis, the results illustrated the value of social gamification for the teaching/learning of privacy and engagement in OSNs. It has also shown that teenagers using the gamified OSN had behaviors that are more restrictive in information disclosure that potentially might reduce actions with negative consequences via practice in a real environment. For the social gamification configuration, we investigated differences in teenagers' learning and engagement taking into account individual characteristics of the participants such as age and gender. The study explored possible age and gender differences regarding the social gamification, depicting only a significant difference for gender (greater for male teenagers than for female teenagers) for the engagement with the educational process.

Our findings and the gamified social platform proposed in this work may be relevant and useful for educators who wish to develop and enhance teenagers' privacy skills, or for a broader base of aspects related to the development of digital competences and technology in education. 


\section{ACKNOWLEDGMENT}

This work was supported by the Spanish Government project TIN2017-89156-R and the FPI grant BES-2015074498 .

\section{REFERENCES}

[1] M. Anderson and J. Jiang, "Teens, social media \& technology 2018," Pew Res. Center: Internet \& American Life Project, vol. 3, p. 2018, May 2018.

[2] E. Vanderhoven, T. Schellens, and M. Valcke, "Educational packages about the risks on social network sites: state of the art," Procedia Social and Behav. Sci., vol. 112, pp. 603-612, Feb. 2014, doi: 10.1016/ j.sbspro.2014.01.1207

[3] A. Sengupta and A. Chaudhuri, "Are social networking sites a source of online harassment for teens? evidence from survey data," Children and Youth Services Rev., vol. 33, no. 2, pp. 284-290, Feb. 2011, doi: 10.1016/j.childyouth.2010.09.011

[4] J. Bauwens, C. Pauwels, C. Lobet-Maris, Y. Poullet, and M. Walrave, "Teens and ict: Risks and opportunities," 2008, [Online]. Available: http://www.belspo.be/belspo/fedra/TA/synTA08_en.pdf. (accessed Aug. $25,2020)$.

[5] S. Livingstone, L. Haddon, A. Görzig, and K. Ólafsson, "Risks and safety on the internet: the perspective of european children: full findings and policy implications from the eu kids online survey of 9-16 year olds and their parents in 25 countries," The London School of Economics and Political Sci., Mar. 2011.

[6] E. Vanderhoven, T. Schellens, R. Vanderlinde, and M. Valcke, "Developing educational materials about risks on social network sites: a design based research approach," Educational Technol. Res. and Develop., vol. 64, no. 3, pp. 459-480, Jun. 2016, doi: 10.1007/s11423-015-9415-4

[7] European Schoolnet (EUN), "Learning resource exchange (lre)," [Online]. Available: http://lreforschools.eun.org/web/guest/insafe (accessed Aug. 25, 2020).

[8] T. D. Brian O'Neill, "The better internet for kids policy map: Implementing the european strategy for a better internet for children in european member states," 2018, [Online]. Available: https://www. betterinternetforkids.eu/bikmap (accessed Aug. 25, 2020).

[9] S. Livingstone and M. Bulger, "A global research agenda for children's rights in the digital age," Journal of Children and Media, vol. 8, no. 4, pp. 317-335, Nov. 2014, doi: 10.1080/17482798.2014.961496

[10] L. N. Zlatolas, T. Welzer, M. Heričko, and M. Hölbl, "Privacy antecedents for sns self-disclosure: The case of facebook," Comput. in Human Behav., vol. 45, pp. 158-167, Apr. 2015, doi: 10.1016/j.chb. 2014.12.012

[11] T. Jagušt, I. Botički, and H.-J. So, "Examining competitive, collaborative and adaptive gamification in young learners' math learning," Comput. \& Educ., vol. 125, pp. 444-457, Oct. 2018, doi: 10.1016/j.compedu.2018. 06.022

[12] S. de Sousa Borges, V. H. S. Durelli, H. M. Reis, and S. Isotani, "A systematic mapping on gamification applied to education," in Proc. 29th Annu. ACM Symp. Applied Computing, ser. SAC '14. New York, NY, USA: Association for Computing Machinery, Mar. 2014, pp. 216-222, doi: $10.1145 / 2554850.2554956$

[13] L. de Marcos, E. Garcia-Lopez, and A. Garcia-Cabot, "On the effectiveness of game-like and social approaches in learning: Comparing educational gaming, gamification \& social networking," Comput. \& Educ., vol. 95, pp. 99-113, Apr. 2016, doi: 10.1016/j.compedu.2015.12.008

[14] S. Chaudron, M. Beutel, V. Donoso Navarrete, M. Dreier, B. FletcherWatson, A. Heikkilä, V. Kontríková, R. Korkeamäki, S. Livingstone, J. Marsh et al., Young children (0-8) and digital technology: A qualitative exploratory study across seven countries. JRC; ISPRA, Italy, 2015.

[15] E. Vanderhoven, "Educating teens about the risks on social network sites. an intervention study in secondary education/enseñar a los adolescentes los riesgos de las redes sociales: Una propuesta de intervención en secundaria," Comunicar, vol. 22, no. 43, p. 123, Jun. 2014, doi: 10.3916/C43-2014-12

[16] G. Britain, Children and parents: Media use and attitudes report. Ofcom, 2013.

[17] J. Davidson, M. Lorenz, J. Grove-Hills, and E. Martellozo, "Evaluation of ceop thinkuknow internet safety programme and exploration of young people's internet safety knowledge," Centre for Abuse and Trauma Studies \& Kingston University \& The Child Exploitation and Online Protection Centre (CEOP), Tech. Rep., May 2009.
[18] T. Spielhofer, Children's Online Risks and Safety: A Review of the Available Evidence. National Foundation for Educational Research, 2010.

[19] S. Livingstone, "Taking risky opportunities in youthful content creation: teenagers' use of social networking sites for intimacy, privacy and selfexpression," New Media \& Society, vol. 10, no. 3, pp. 393-411, Jun. 2008, doi: 10.1177/1461444808089415

[20] M. Inoue, T. Imado, and M. Higasino, "Development of a computerized educational tool and practical lesson about safety on social networking service," in Proc. 2017 9th Int. Conf. Education Technology and Computers, ser. ICETC 2017. New York, NY, USA: ACM, Dec. 2017, pp. 149-152, doi: $10.1145 / 3175536.3175538$

[21] H. Wang, "Developing online privacy education tools with inputs from the crowd," in 22nd Americas Conf. on Information Systems, Aug. 2016.

[22] W. Wang, Y. Tao, K. Wang, D. Jedruszczak, and B. Knutson, "Leveraging crowd for game-based learning: A case study of privacy education game design and evaluation by crowdsourcing," arXiv preprint arXiv:1603.02766, 2016.

[23] N. Li, V. Chava, and L. Li, "A labware for educating location privacy protection in location-based services," Journal of Computing Sci. in Colleges, vol. 32, no. 4, pp. 40-48, Apr. 2017.

[24] R. Roopchund, V. Ramesh, and V. Jaunky, "Use of social media for improving student engagement at université des mascareignes (udm)," in Inf. Systems Design and Intelligent Applications. Springer, 2019, pp. 11-20.

[25] A. Habibi, A. Mukinin, Y. Riyanto, L. D. Prasohjo, U. Sulistiyo, M. Sofwan, and F. Saudagar, "Building an online community: Student teachers' perceptions on the advantages of using social networking services in a teacher education program," Turkish Online Journal of Distance Educ., vol. 19, no. 1, pp. 46-61, Jan. 2018, doi: 10.17718/ tojde. 382663

[26] C. H.-H. Tsay, A. Kofinas, and J. Luo, "Enhancing student learning experience with technology-mediated gamification: An empirical study," Comput. \& Educ., vol. 121, pp. 1-17, Jun. 2018, doi: 10.1016/j. compedu.2018.01.009

[27] J. Hamari, "Do badges increase user activity? a field experiment on the effects of gamification," Comput. in human Behav., vol. 71, pp. 469-478, Jun. 2017, doi: 10.1016/j.chb.2015.03.036

[28] D. Dicheva, C. Dichev, G. Agre, and G. Angelova, "Gamification in education: a systematic mapping study," Educational Technol. \& Society, vol. 18 , no. 3, pp. 75-89, Jul. 2015

[29] M. D. Hanus and J. Fox, "Assessing the effects of gamification in the classroom: A longitudinal study on intrinsic motivation, social comparison, satisfaction, effort, and academic performance," Comput. \& Educ., vol. 80, pp. 152-161, Jan. 2015, doi: 10.1016/j.compedu.2014.08.019

[30] A. M. Toda, R. M. do Carmo, A. P. da Silva, I. I. Bittencourt, and S. Isotani, "An approach for planning and deploying gamification concepts with social networks within educational contexts," Int. Journal of Inf. Manage., vol. 46, pp. 294-303, Jun. 2018, doi: 10.1016/j.ijinfomgt. 2018.10.001

[31] A. Acquisti, I. Adjerid, R. Balebako, L. Brandimarte, L. F. Cranor, S. Komanduri, P. G. Leon, N. Sadeh, F. Schaub, M. Sleeper et al., "Nudges for privacy and security: Understanding and assisting users' choices online," ACM Comput. Surv., vol. 50, no. 3, p. 44, Aug. 2017, doi: $10.1145 / 3054926$

[32] W. M. Al-Rahmi, N. Alias, M. S. Othman, V. I. Marin, and G. Tur, "A model of factors affecting learning performance through the use of social media in malaysian higher education," Comput. \& Educ., vol. 121, pp. 59-72, Jun. 2018, doi: 10.1016/j.compedu.2018.02.010

[33] J. Koivisto and J. Hamari, "Demographic differences in perceived benefits from gamification," Comput. in Human Behav., vol. 35, pp. 179-188, Jun. 2014, doi: 10.1016/j.chb.2014.03.007

[34] L. Z. Pedro, A. M. Z. Lopes, B. G. Prates, J. Vassileva, and S. Isotani, "Does gamification work for boys and girls? an exploratory study with a virtual learning environment," in Proc. 30th Annu. ACM Symp. Applied Computing, ser. SAC '15. New York, NY, USA: Association for Computing Machinery, Apr. 2015, pp. 214—219, doi:10.1145/2695664. 2695752

[35] V. J. Rideout, Social media, social life: How teens view their digital lives. Common Sense Media, 2012

[36] M. Madden, A. Lenhart, S. Cortesi, U. Gasser, M. Duggan, A. Smith, and M. Beaton, "Teens, social media, and privacy," Pew Res. Center, vol. 21, pp. 2-86, May 2013.

[37] G. S. O'Keeffe, K. Clarke-Pearson et al., "The impact of social media on children, adolescents, and families," Pediatrics, vol. 127, no. 4, pp. 800-804, Apr. 2011, doi: 10.1542/peds.2011-0054 
[38] S. Livingstone, "Taking risky opportunities in youthful content creation: teenagers' use of social networking sites for intimacy, privacy and selfexpression," New media \& society, vol. 10, no. 3, pp. 393-411, Jun. 2008, doi: 10.1177/1461444808089415

[39] P. Byron, K. Albury, and C. Evers, "It would be weird to have that on facebook: young people's use of social media and the risk of sharing sexual health information," Reproductive health matters, vol. 21, no. 41, pp. 35-44, May 2013, doi: 10.1016/S0968-8080(13)41686-5

[40] Valencian Research Institute for Artificial Intelligence. (2016) Pesedia projects website. [Online]. Available: https://pesedia.webs.upv.es (accessed Aug. 25, 2020).

[41] J. Alemany, E. del Val, J. Alberola, and A. García-Fornes, "Estimation of privacy risk through centrality metrics," Future Generation Computer Systems, vol. 82, pp. 63-76, May 2018, doi: 10.1016/j.future.2017.12. 030

[42] J. Alemany, E. Del Val, J. M. Alberola, and A. Garćia-Fornes, "Metrics for privacy assessment when sharing information in online social networks," IEEE Access, vol. 7, pp. 143631-143645, Sep. 2019, doi: 10.1109/ACCESS.2019.2944723

[43] J. Alemany, E. del Val, J. Alberola, and A. García-Fornes, "Enhancing the privacy risk awareness of teenagers in online social networks through soft-paternalism mechanisms," Int. Journal of Human-Comput. Stud. vol. 129, pp. 27-40, Sep. 2019, doi: 10.1016/j.ijhcs.2019.03.008

[44] J. Alemany, E. Del Val, and A. García-Fornes, "Empowering users regarding the sensitivity of their data in social networks through nudge mechanisms," in Proc. 53rd Hawaii Int. Conf. System Sciences, Jan. 2020, pp. 2539-2548, doi: $10.24251 /$ HICSS.2020.310

[45] C. Costello, Elgg 1.8 social networking. Packt Publishing Ltd, 2012.

[46] G. Zichermann and C. Cunningham, Gamification by design: Implementing game mechanics in web and mobile apps. O'Reilly Media, Inc., 2011.

[47] S. E. Dreyfus and H. L. Dreyfus, "A five-stage model of the mental activities involved in directed skill acquisition," California Univ. Berkeley Operations Research Center, Tech. Rep., 1980.

[48] Y. Wang, P. G. Leon, X. Chen, and S. Komanduri, "From facebook regrets to facebook privacy nudges," Ohio St. LJ, vol. 74, pp. 1307 1334, 2013.

[49] D. J. Solove, Understanding privacy. Harvard university press Cambridge, MA, 2008, vol. 173.

[50] A. Acquisti, L. Brandimarte, and G. Loewenstein, "Privacy and human behavior in the age of information," Science, vol. 347, no. 6221, pp. 509-514, Jan. 2015, doi: $10.1126 /$ science.aaa1465

[51] C. E. Tucker, "Social networks, personalized advertising, and privacy controls," Journal of Marketing Res., vol. 51, no. 5, pp. 546-562, Oct. 2014, doi: $10.1509 /$ jmr.10.0355

[52] J. Hamari, J. Koivisto, and H. Sarsa, "Does gamification work? - a literature review of empirical studies on gamification," in 2014 47th Hawaii Int. Conf.System Sciences. IEEE, Jan. 2014, pp. 3025-3034, doi: 10.1109/HICSS.2014.377

[53] W. Xie and C. Kang, "See you, see me: Teenagers' self-disclosure and regret of posting on social network site," Comput. in Human Behav. vol. 52, pp. 398-407, Nov. 2015, doi: 10.1016/j.chb.2015.05.059

[54] M. Yang, Y. Yu, A. K. Bandara, and B. Nuseibeh, "Adaptive sharing for online social networks: A trade-off between privacy risk and social benefit," in 2014 IEEE 13th Int. Conf. Trust, Security and Privacy in Computing and Communications. IEEE, Sep. 2014, pp. 45-52, doi: 10.1109/TrustCom.2014.10

[55] A. C. Squicciarini, F. Paci, and S. Sundareswaran, "Prima: a comprehensive approach to privacy protection in social network sites," Ann. of Telecommun., vol. 69, no. 1-2, pp. 21-36, Feb. 2014, doi: 10.1007/s12243-013-0371-x

[56] S. J. De and A. Imine, "To reveal or not to reveal: Balancing usercentric social benefit and privacy in online social networks," in Proc. 33rd Annu. ACM Symp. Applied Computing, ser. SAC '18, ACM. New York, NY, USA: Association for Computing Machinery, Apr. 2018, pp. 1157-1164, doi: $10.1145 / 3167132.3167258$

[57] K. M. Kapp, The gamification of learning and instruction: game-based methods and strategies for training and education. John Wiley \& Sons, 2012.

[58] D. Rozen, M. Askalani, and T. Senn, "Staring at the sun: identifying, understanding and influencing social media users," Res. brief: Aimia Inc., 2012.

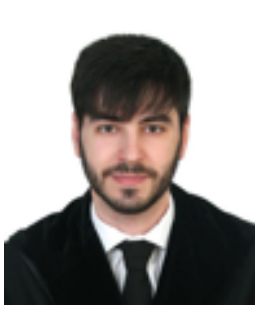

J. Alemany received the Master's degree in Informatics Engineering at Universitat Politècnica de València (UPV) in 2016. He is currently pursuing the Ph.D. degree under the supervision of Dr. Ana García-Fornes and Dr. Elena Del Val, and is supported by a Spanish FPI grant. His research interests include information dissemination, privacypreserving, content analysis, and complex networks.

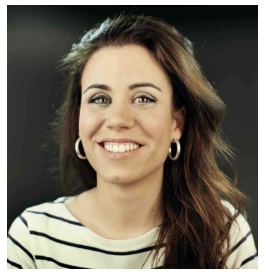

E. Del Val is an Assistant Professor at Universidad de Zaragoza. She obtained the M.Sc. Degree in Computer Science from the UPV in 2006 and the Master Degree in Artificial Intelligence, Pattern Recognition, and Digital Image in 2009. She received the Ph.D. degree with European mention from the UPV in 2013. She has participated in several research projects related to Multi-agent Systems, Service Oriented Computing, and Artificial Intelligence. Currently, she is working on intelligent analysis of social network dynamics.

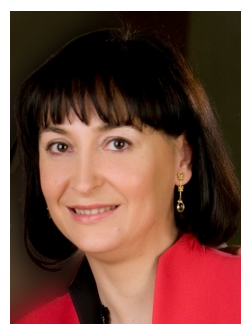

A. García-Fornes received her B.S.(1986) and Ph.D.(1996) degrees in Computer Science from the Polytechnic University of Catalonia, Spain, and the Valencia University of Technology, Spain, respectively. She currently works as a Full Professor at the Department of Information Systems and Computation at the Valencia University of Technology, Spain. Her research interests focus on real-time scheduling, real-time operating systems, real-time agent/multiagent systems, and multi-agent system platforms. 